\title{
Effects on C-phycocyanin content of Arthrospira platensis of culture medium containing geothermal water
}

\author{
Betul Kut Guroy ${ }^{a}$, Sibel Bayil Oguzkan ${ }^{\text {b,* }}$ \\ a Yalova University, Armutlu Vocational School, Food Processing Technology Department, Yalova, TR \\ ${ }^{b}$ Gaziantep University, Vocational School of Health Services, Department of Medical Services and Techniques, Gaziantep, TR
}

\begin{tabular}{l}
\hline ARTICLE INFO \\
\hline Article History: \\
Received: 28 July 2021 \\
Revised: 20 August 2021 \\
Accepted: 20 August 2021 \\
Available online: 22 August 2021 \\
Edited by: B. Tepe \\
Keywords: \\
Arthrospira platensis \\
Geothermal water \\
C-phycocyanin \\
Freeze-drying \\
Purity ratio
\end{tabular}

\section{Introduction}

Arthrospira platensis is one of the critical species belong to Cyanobacteria. A. platensis and A. maxima are known as "Spirulina" common names. Spirulina is used as "a healthy food source" for humans with nutrient composition (Moejes and Moejes, 2017), for "enrichment of soil" in an agricultural area (Anitha et al., 2016), as "animal feed" in the production of livestock and economic aquatic organism (Chakdar et al., 2012). Spirulina can be contained approximately $46-70 \%$ protein and $20 \%$ phycocyanin of dry weight (Liong, 2011). Phycocyanin is a natural dye and has a pharmaceutical effect via its pigment-protein complex. Also, phycocyanin can help regulate various essential enzymes needed to synthesize human metabolism, inhibit cancer cell growth, and promote human cell regeneration. Oncologists have recommended phycocyanin due to pharmaceutical effects (Küçük et al., 2017). Nevertheless, the produ-

\footnotetext{
* Corresponding author:

E-mail address: bayil@gantep.edu.tr (S. Bayil Oguzkan)

ISSN: 2149-6307

doi: http://dx.doi.org/10.20863/nsd.v4i3.61

(c) 2021 NSD. Published by Lycia Press London. All rights reserved.
}

\begin{abstract}
This research aimed to compare effects on product quality and algal growth of inoculation ratio of the ratio of $1 / 6,1 / 10$, and $1 / 20$ of nutrient medium volume $(2500 \mathrm{~mL})$. The experiment medium was prepared with 20\% geothermal water and $80 \%$ distilled water. Schlosser medium, 100\% geothermal water $20 \%$ geothermal water medium. Among the experimental groups, dry biomass was obtained in the Spirulina $1.259\left(\mathrm{~A}_{750}\right)$, and the biomass yield was $0.928 \mathrm{~g} / \mathrm{L}$. The most efficient growth and phycocyanin content was determined in the $1 / 6$ inoculated groups. The phycocyanin content in the experimental group was found in determined in the Schlösser medium. While $48.42 \%$ protein was detected in the geothermal water group dium
\end{abstract}

C 2021 NSD. Published by Lycia Press London. All rights reserved. ction costs are limiting the use of Spirulina in these areas. Spirulina production with high efficiency at low-costs is one of the most critical areas studied. The most essential shareholders between production costs cover components of culture medium. $\mathrm{NaHCO}_{3}$ is a macro component affecting the price of Spirulina culture. Schlösser medium (Schlösser, 1994) and Zarrouk medium (Zarrouk, 1966) are practicable for Spirulina cultivation that contains $13.61 \mathrm{~g}$ and $16.8 \mathrm{~g}$ $\mathrm{NaHCO}_{3}$ per liter, respectively.

The geothermal water of Armutlu (Yalova, Turkey) can be characterized as a culture medium of $A$. platensis due to contains micro and macronutrients. Geothermal water can have significant macro and micronutrients required for microalgae cultivation and are an important potential for Spirulina production as a culture medium. This research was conducted to perform Spirulina production that can be harvested with a culture medium containing $20 \%$ geothermal water and $80 \%$ distilled water and to evaluate geothermal water as Spirulina culture medium.

2. Materials and methods 


\subsection{Culture conditions}

The geothermal water used for Spirulina culture was obtained from wells in Armutlu-Yalova of Turkey (Armutlu, Turkey, $\left.40^{\circ} 31^{\prime} 10^{\prime \prime} \mathrm{N} / 28^{\circ} 49^{\prime} 41^{\prime \prime} \mathrm{E}\right)$. A. platensis, was inoculated into standard mineral medium (Schlösser, 1994) and cultured in an orbital shaker for 13 days, illuminated at 1000 lux and cultured at $30{ }^{\circ} \mathrm{C}$ and reached a density of $1.34\left(\mathrm{~A}_{750}\right)$ (Gomont, 1893). In all experimental groups, A. platensis was inoculated with an optical density of 1.34 in the starter cultures. Some components of Armutlu geothermal water and Schlösser Spirulina medium are shown in Table 1.

Table 1. Some nutrient components of experiment culture medium

\begin{tabular}{llll}
\hline Medium & $\mathrm{pH}$ & $\mathrm{NaHCO}_{3}(\mathrm{mg} / \mathrm{L})$ & $\mathrm{NO}_{3}(\mathrm{mg} / \mathrm{L})$ \\
\hline Schlösser Spirulina Medium & 8.34 & 16.8 & 2.5 \\
Pure geothermal water & 7.2 & 1140.0 & 11.0 \\
20\% geothermal water & 7.3 & 228.7 & 2.2 \\
\hline
\end{tabular}

\subsection{Trial design}

The trial was composed of 12 experimental groups, and two replicates were designed. A. platensis was inoculated at 1/6, 1/10, and $1 / 20$ of the culture medium volume $(2500 \mathrm{~mL}) .100 \%$ distilled water, $100 \%$ geothermal water, and Schlösser Spirulina medium (Schlösser, 1994) were used as the control group. In the experimental group, $80 \%$ distilled water with $20 \%$ geothermal water mixture was prepared in $2500 \mathrm{~mL}$ volume. All groups were designed to duplicate. The $\mathrm{pH}$ of the prepared formulation was measured as 8.11 .

\%20 geothermal water replacement group instead of Schlösser Spirulina medium was not prepared. Each group was cultured in a 5 L erlenmayer for 19 days. The temperature, $\mathrm{pH}$, and optical density values of the culture medium $\left(A_{750}\right)$ were measured and recorded daily.

\subsection{Harvesting of $A$. platensis}

At the end of the experiment, Spirulina biomass was obtained by filtering from 80-micron plankton cloth. The harvested biomass was dried at $-60{ }^{\circ} \mathrm{C}$ by freeze-drying method. Spirulina powder was obtained by using the grinder mill after freeze-drying.

\subsection{Analysis of Spirulina}

The protein content of Spirulina was determined by Thiex et al. (2002). The spectrometrical method was performed via phycocyanin analysis. C-phycocyanin content was calculated according to Setyoningrum and Nur (2015) and Boussiba and Richmond (1979). Phycocyanin has a single visible absorbance maximum between 615 and $620 \mathrm{~nm}$. The method followed is to extract blue supernatant; the dry weight of Spirulina powder was calculated after dried in the oven at $80^{\circ} \mathrm{C}$ for six $\mathrm{h}$. To determine the percentage of phycocyanin, $40 \mathrm{mg}$ of Spirulina was weighed, $10 \mathrm{~mL}$ of phosphate buffer (100 $\mathrm{mM}$ ) added and stirred until complete dissolution. The samples were stored in the refrigerator at $4{ }^{\circ} \mathrm{C}$ overnight. The samples were subsequently mixed in the centrifuge at $10{ }^{\circ} \mathrm{C}$, at $3500 \mathrm{rpm}$ for 5 min. After centrifugation, blue supernatant was reserved for spectrophotometric analysis. The analysis procedure was conducted in triplicate. After centrifuge, blue supernatant was separated from residue. The absorbance value of blue supernatant was read in a spectrophotometer at $620 \mathrm{~nm}$ using phosphate buffer as blank. Phycocyanin was calculated according to the following equation.

$$
\% \text { C- Phycocyanin }=\frac{[A(620) \times 10 \times 100]}{7,3 \times \text { sample }(\mathrm{mg}) \times(\% \text { dry weight })}
$$

$\mathrm{A}(620)$ is the absorbance at $620 \mathrm{~nm}, 10$ is the dilution volume, 100 is the representative of $100 \%$, and 3.36 is the extinction coefficient for phycocyanin at $620 \mathrm{~nm}$.

The C-phycocyanin purity ratio is considered the food-grade when $A_{620} / A_{280}$ is $\geq 0.7$, and as the reagent grade when $A_{620} / A_{280}$ is between 0.7 and 3.9; and as an analytical grade when $A_{620} / A_{280}$ is $\geq$ 4.0. C-phycocyanin purity ratio was calculated using the spectrophotometry-based method on the absorbance ratio $A_{620} / A_{280}$ (Antelo et al., 2010). Calculations of purity ratio are given below;

$$
\text { C-pycocyanin purity ratio }=A(620) / A(280)
$$

The data obtained from the experiment were subjected to a oneway analysis of variance.

\section{Results and discussion}

Only the group inoculated of $1 / 6$ ratio in $20 \%$ geothermal water was successfully grown and harvested among the experimental groups. In all groups of Schlösser medium was observed successful culture growth. The best culture growth among the experimental groups was obtained in the group, which was $1 / 6$. The optical density changes during the experiments are shown in Figure 1, Figure 2 and Figure3, Figure 4, Figure 5, and Figure 6. During the trial, the temperature was measured at $26-28{ }^{\circ} \mathrm{C}$. The $\mathrm{pH}$ values in the successful experimental group (Figure 7) were higher than the control groups with $1 / 10$ (Figure 11) and $1 / 20$ (Figure 12) inoculating. The changes in $\mathrm{pH}$ are shown in Figure 7 , Figure 8 , Figure 9, Figure10, Figure 11, and 12. In the $1 / 20$ inoculated experimental group, both the retention phase lasted longer, and the lowest growth was observed. Successful culture growth could not be achieved in $1 / 10$ and $1 / 20$ inoculated experiment groups. When harvested on day 19 , in the $1 / 6$ experimental group, the optical density (Figure 1) value was determined as $0.989\left(A_{750}\right)$, and the yield of biomass was $0.478 \mathrm{~g}$. In $1 / 6$ Schlösser medium, $1.259\left(A_{750}\right)$ optical density (Figure 4) and $0.928 \mathrm{~g} / \mathrm{L}$ yield of biomass was found. In $1 / 10$ and $1 / 20$ groups of Schlösser, optical density and dry biomass yield were found $1.24\left(\mathrm{~A}_{750}\right)$ (Figure 5 ) and $0.528 \mathrm{~g} / \mathrm{L}$ and $1.06\left(A_{750}\right)$ (Figure 6$)$ and $0.428 \mathrm{~g} / \mathrm{L}$, respectively.

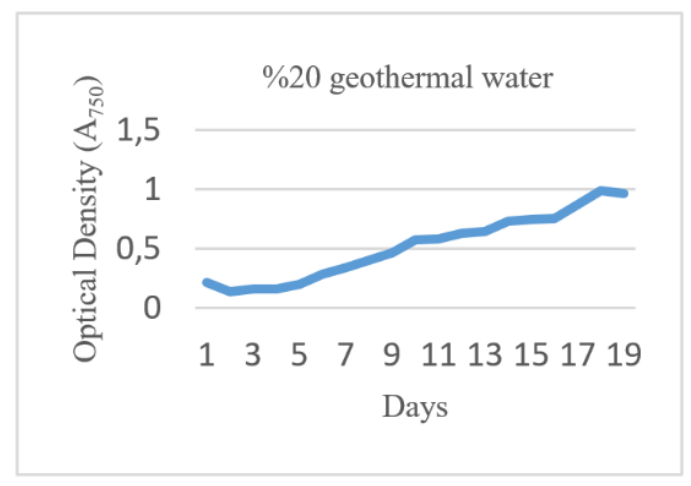

Figure 1. Variation of optical density with1:5 inoculation ratio 


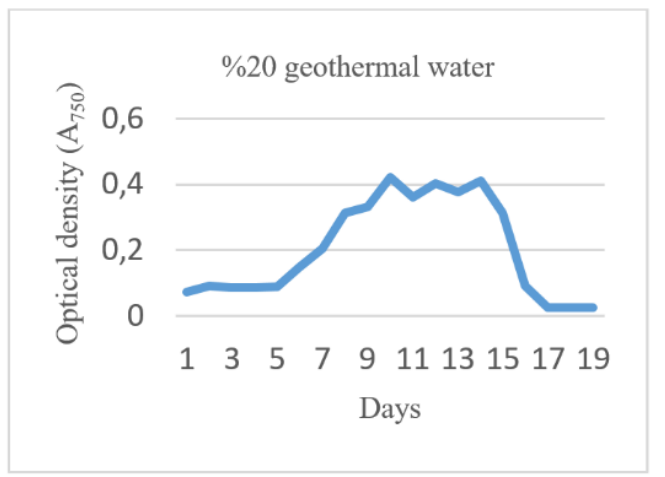

Figure 2. Variation of optical density with1:10 inoculation

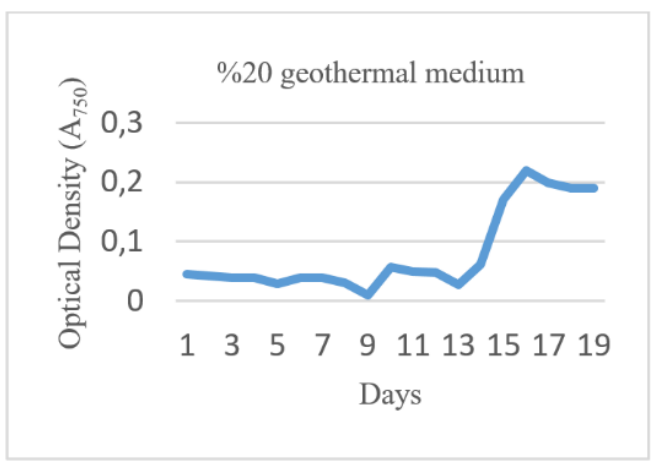

Figure 3. Variation of optical density with1:20 inoculation

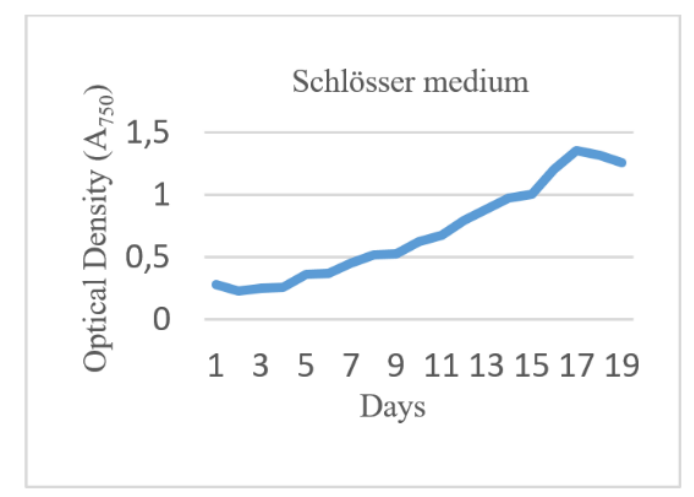

Figure 4. Variation of optical density with1:5 inoculation

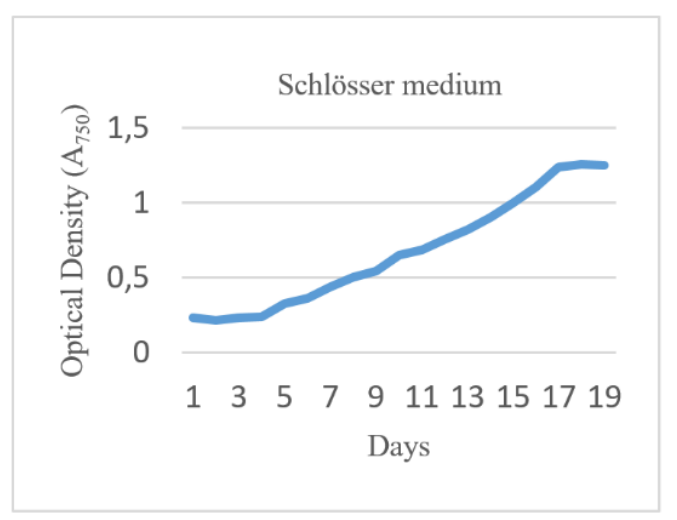

Figure 5. Variation of optical density with1:10 inoculation

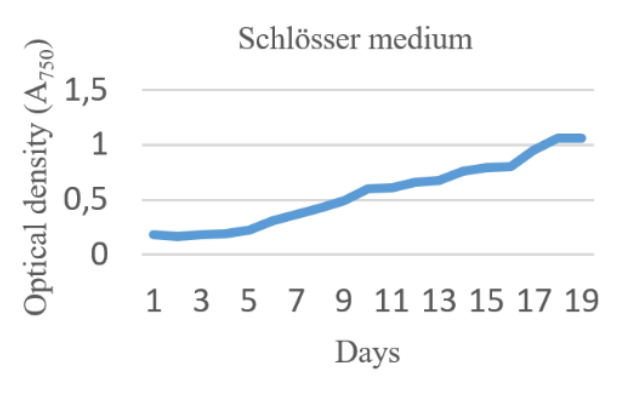

Figure 6. Variation of optical density with1:20 inoculation

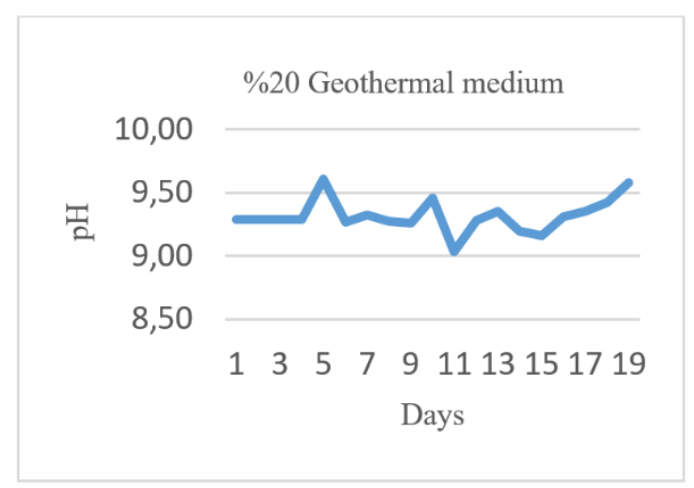

Figure 7. $\mathrm{pH}$ evolution during the cultivations in 1:5 group

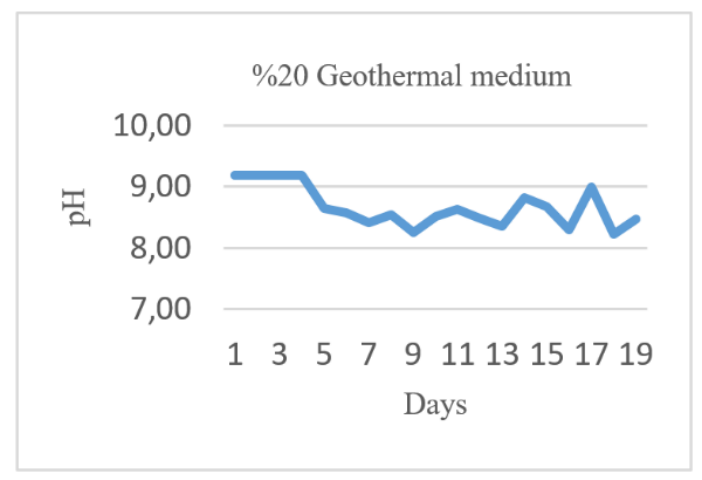

Figure 8. pH evolution during the cultivations in 1:10 group

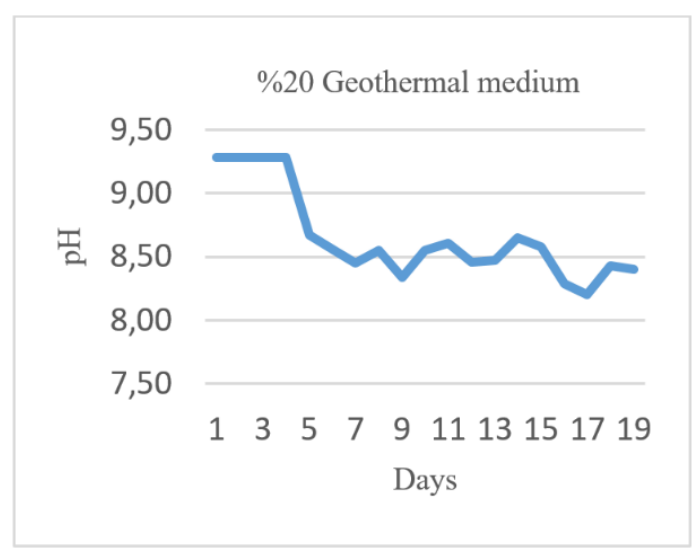

Figure 9. $\mathrm{pH}$ evolution during the cultivations in 1:20 group 


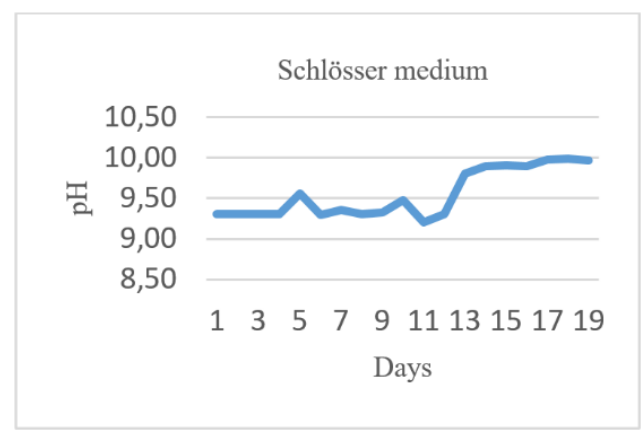

Figure 10. $\mathrm{pH}$ evolution during the cultivations in 1:5 group

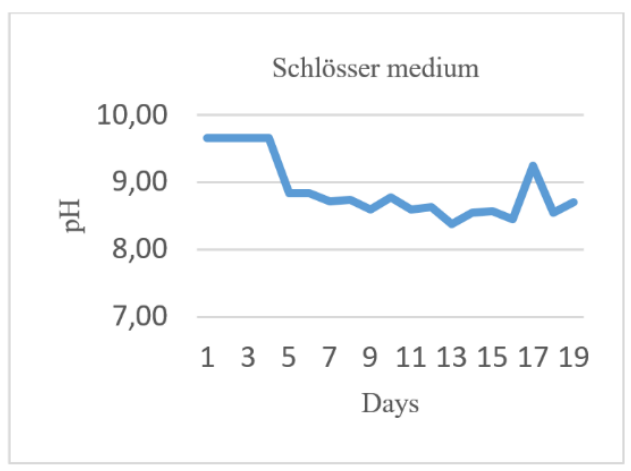

Figure 11. pH evolution during the cultivations in 1:10 group

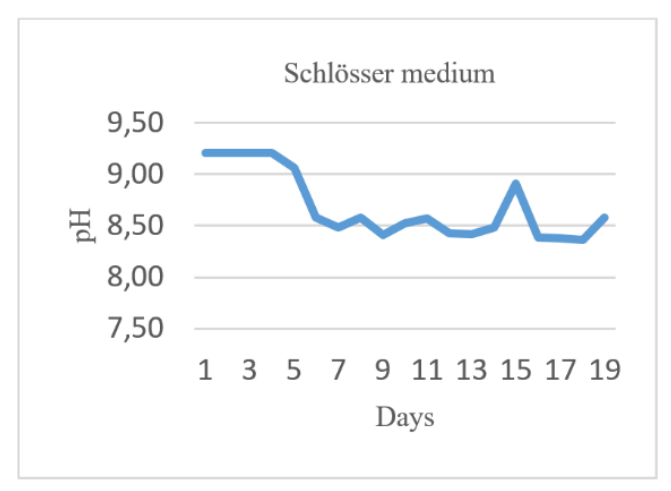

Figure 12. pH evolution during the cultivations in 1:20 group

Phycocyanin, a blue pigment, can be easily extracted from Spirulina. The purity of phycocyanin is an essential factor that determines its application area. The C-phycocyanin purity ratio is considered as the food-grade when $A_{620} / A_{280}$ is $\geq 0.7$, and as the reagent grade when $A_{620} / A_{280}$ is between 0.7 and 3.9 , and as an analytical grade when $A_{620} / A_{280}$ is $\geq 4.0$ (Antelo et al., 2010; Kuddus et al., 2013).

The phycocyanin content and purity ratio were found $22.49 \%$ and 2.24 , respectively, in the $1 / 6$ experimental group. 3.73 purity ratio and $28.62 \%$ phycocyanin content were determined in $1 / 6$ inoculated Schlösser group.

Phycocyanin is not a high-temperature resistant pigment (Güroy et al., 2017). The phycocyanin content obtained in this study was extracted from freeze-dried Spirulina. Therefore, it was concluded that high-efficiency phycocyanin content (\%) was analyzed. However, to reach precise results, it is necessary to carry out the studies of phycocyanin in detail.
Spirulina is one of the best protein sources containing essential amino acids. While $48.42 \%$ protein was detected in the geothermal water group, $61.64 \%$ was obtained with the Schlösser medium. The protein and phycocyanin values are presented in Table 2 .

Table 2. Protein and phycocyanin values of $A$. platensis in different culture medium

\begin{tabular}{llll}
\hline Groups & $\begin{array}{l}\text { Protein } \\
(\%)\end{array}$ & Phycocyanin (\%) & $\begin{array}{l}\text { Purity ratio of } \\
\text { phcocyanin } \\
\left(\mathrm{A}_{620} / \mathrm{A}_{280}\right)\end{array}$ \\
\hline 1:5 Geothermal medium & $48.42^{\mathrm{b}}$ & $22.49^{\mathrm{c}}$ & $2.24^{\mathrm{b}}$ \\
1:5 Schlösser medium & $61.64^{\mathrm{a}}$ & $28.62^{\mathrm{b}}$ & $3.73^{\mathrm{a}}$ \\
1:10 Schlösser medium & $58.54^{\mathrm{a}}$ & $20.84^{\mathrm{a}}$ & $2.20^{\mathrm{b}}$ \\
1:20 Schlösser medium & $59.80^{\mathrm{a}}$ & $21.94^{\mathrm{c}}$ & $2.37^{\mathrm{b}}$ \\
\hline
\end{tabular}

In this research, the purity ratio of the phycocyanin obtained in both the experimental and control groups was determined as the reagent grade. Culture growth with $100 \%$ distilled water and 100\% geothermal water were not observed. However, it can be said that geothermal water continues to give hope based on our unpublished works (Güroy et al., 2018). Moreover, the rate of culture inoculating influenced the growth of the culture. This effect was seen in both control and experiment groups (Figures 1, 2, 3, 4, 5, and 6). Although there was a significant effect in the experimental group, $1 / 10$ and $1 / 20$ inoculating ratios were unsuccessful (Figures 1, 2, and 3). Since the Schlösser nutrient medium contains enough minerals, the inoculation ratio was positively affected. However, the group containing geothermal water was already formulated with distilled water. Therefore, the inadequacy of certain nutrients resulted in each culture being ineffective at a certain inoculation ratio and achieving a low protein value. The results will be different if geothermal water is used instead of Schlösser's medium. The use of geothermal water in Spirulina production is carried out globally (Fournadzhieva et al., 2003; Godlewska et al., 2015; Lund and Boyd, 2016). However, the determination of usable geothermal waters in Spirulina production is an important research topic.

Geothermal water is a potential energy source for heating the enterprise and drying of Spirulina for up to 12 months and potential as a nutrient medium for Spirulina.

\section{Conclusions}

Nowadays, with the awareness of the harmful effects of synthetic compounds and natural products, it has increased to consider microalgae as a natural pigment source. In this study, an acceptable purity ratio was obtained with geothermal water. However, it is advisable to diversify the trials to get a tremendous amount of phycocyanin.

\section{Acknowledgments}

The author would like to thank Armutlu Municipality for supporting this work. This study was presented national aquaculture symposium 2017 Sinop, Turkey.

\section{Conflict of Interest}

The authors confirm that there are no known conflicts of interest.

\section{CRediT authorship contribution statement}

Betul Kut Guroy: Conceptualization, Data curation, Methodology, Resources, Visualization. 
Sibel Bayil Oguzkan: Conceptualization, Data curation, Formal analysis, Investigation, Methodology, Resources, Visualization, Writing - original draft.

\section{ORCID IDs of the Authors}

\section{B. Kut Guroy: 0000-0002-4298-6256}

S. Bayil Oguzkan: 0000-0003-0254-6915

\section{Supplementary file}

None.

\section{References}

Anitha, L., Bramari, G.S., Kalpana, P., 2016. Effect of supplementation of Spirulina platensis to enhance the zinc status in plants of Amaranthus gangeticus, Phaseolus aureus and tomato. Advances in Bioscience and Biotechnology, 7, 289-299.

Antelo, F.S., Anschau, A., Costa, J.A., Kalil, S.J., 2010. Extraction and purification of C phycocyanin from Spirulina platensis in conventional and integrated aqueous two phase systems. Journal of the Brazilian Chemical Society, 21, 921-926.

Boussiba, S., Richmond, A.E., 1979. Isolation and characterization of phycocyanins from the blue-green alga Spirulina platensis. Archives of Microbiology, 120, 155-159.

Chakdar, H., Jadhav, S.D., Dhar, D.W., Pabbi, S., 2012. Potential applications of blue green algae. Journal of Scientific \& Industrial Research, 71, 13-20.

Fournadzhieva, S., Bojadgieva, K., Pilarski, P., 2003. Bulgarian experience in aquacultur (microalgae)-cultivation, production and development, European Geotherma Conference Szeged, Hungary, pp. 25-30.

Godlewska, K., Tomaszewska, B., Michalak, I., Bujakowski, W., Chojnacka, K., 2015 Prospects of geothermal water Use in cultivation of Spirulina. Open Chemistry, 13 1218-1227.

Gomont, M., 1893. Monographie des Oscillariées (Nostocacées Homocystées) Deuxième partie. - Lyngbyées. Annales des Sciences Naturelles, Botanique, Série 7 , $16,91-264$

Güroy, B., Güroy, D., Mantoğlu, S., Karadal, O., Oğuzkan, S., 2018. The Effect of the GeothermalWater on Protein Content of Spirulina in Greenhouse Condition, International Agricultural Science Congress, Van-Turkey.

Güroy, B., Karadal, O., Mantoğlu, S., Cebeci, O.I., 2017. Effects of different drying methods on C-phycocyanin content of Spirulina platensis powder. Su Ürünleri Dergisi, 34, 129-132.

Kuddus, M., Singh, P., Thomas, G., Al-Hazimi, A. 2013, Recent developments in production and biotechnological applications of C-phycocyanin. BioMed Research International, 2013, 742-859.

Küçük, Ö., Güney, K., Evcin, Ö., Aktürk, E., 2017. Threat Analysis and Proposed Solutions for Elekdag Wildlife Development Area. MESMAP-3 ABSTRACT BOOK, 60.

Liong, M.-T., 2011. Bioprocess Sciences and Technology. Nova Science Publ.

Lund, J.W., Boyd, T.L., 2016. Direct utilization of geothermal energy 2015 worldwide review. Geothermics, 60, 66-93.

Moejes, F.W., Moejes, K.B., 2017. Algae for Africa: Microalgae as a source of food, feed and fuel in Kenya. African Journal of Biotechnology, 16, 288-301.

Schlösser, U.G., 1994. SAG-Sammlung von Algenkulturen at the University of Göttingen Catalogue of Strains 1994. Botanica Acta, 107, 113-186.

Setyoningrum, T.M., Nur, M.A., 2015. Optimization of C-phycocyanin production from S. platensis cultivated on mixotrophic condition by using response surface methodology. Biocatalysis and Agricultural Biotechnology, 4, 603-607.

Thiex, N.J., Manson, H., Anderson, S., Persson, J.-Å., 2002. Determination of crude protein in animal feed, forage, grain, and oilseeds by using block digestion with a copper catalyst and steam distillation into boric acid: collaborative study. Journal of AOAC International, 85, 309-317.
Zarrouk, C., 1966. Contribution a l'etude d'une cyanobacterie: influence de divers facteurs physiques et chimiques sur la croissance et la photosynthese de Spirulina maxima (Setchell et Gardner) Geitler. University of Paris, France. 